\title{
PENCEGAHAN SERANGAN DISMINORE DENGAN PENERAPAN SENAM DISMINORE BAGI REMAJA DI SMK 3 MUHAMMADIYAH PALEMBANG
}

\author{
Yuniza $^{1}$, Ida Nurjannah ${ }^{2}$ \\ ${ }^{1}$ Dosen Program Studi Ilmu Kepetrawatan IKesT Muhammadiyah Palembang \\ ${ }^{2}$ Mahasiswa Program Studi Ilmu Kepetrawatan IKesT Muhamamdiyah Palembang \\ Email: yuniza88@gmail.com, nurjannah@gmail.com
}

\begin{abstract}
ABSTRAK
Kesehatan reproduksi menurut Undang Undang Republik Indonesia No. 36 tahun 2009 tentang Kesehatan pada pasal 71 mencakup kesehatan saat sebelum hamil, ketika dan sesudah melahirkan, pengaturan kehamilan, alat kontrasepsi, kesehatan seksual serta kesehatan sistem reproduksi. Kesehatan reproduksi membahas proses, fungsi dan sistem reproduksi pada semua tahap kehidupan. Kesehatan reproduksi pada wanita terdiri dari kesehatan reproduksi ibu dan anak, remaja, dan usia lanjut. Masa remaja merupakan masa transisi dari masa kanak-kanak ke masa dewasa, dimana seorang manusia sedang berada dalam pencarian jati dirinya, ingin mengenal siapa dirinya sebenarnya. Pada masa ini terjadi berbagai perubahan dan perkembangan yang cepat, baik fisik mental maupun psikososial. Tidak sedikit permasalahan dalam kehidupan remaja terutama adalah dalam masa kesehatan reproduksi. Tujuan dari program ini adalah menerapkan senam disminore untuk mengatasi serangan awal disminore pada siswi SMK 3 Muhammadiyah Palembang. Hasil pengukuran nyeri disminore sebelum dilakukan senam disminore yaitu pada tahap nyeri ringan kemudian setelah dilakukan senam disminore rentang nyeri pada kriteria tidak nyeri. Dari 33 responden pengabdian masyarakat gejala yang ditimbulkan sebagian besar yaitu nyeri timbul saat sebelum dan selama menstruasi dalam 24 jam.
\end{abstract}

Kata Kunci: Disminore, Pencegahan, Senam Disminore, Remaja

\section{PREVENTION OF DISMINORE ATTACKS WITH THE APPLICATION DISMINORE EXERCISE FOR YOUTH IN SMK 3 MUHAMMADIYAH PALEMBANG}

\begin{abstract}
Reproductive health according to the Law of the Republic of Indonesia No. 36 of 2009 concerning Health in article 71 covers health before pregnancy, during and after childbirth, pregnancy management, contraception, sexual health and the health of the reproductive system. Reproductive health addresses the reproductive processes, functions and systems at all stages of life. Reproductive health in women consists of reproductive health for mothers and children, adolescents, and the elderly. Adolescence is a period of transition from childhood to adulthood, where a human being is in search of his identity, wanting to know who he really is. During this period there were various changes and rapid developments, both physically, mentally and psychosocial. Not a few problems in adolescent life, especially in the period of reproductive health. The aim of this program is to apply dysminore gymnastics to overcome the initial attack of dysminore on students of SMK 3 Muhammadiyah Palembang. The results of the measurement of dysminorrhea pain before doing dysminorrhea exercise were in the mild pain stage, then after the dysminorrhea exercise was carried out the pain range was in the painless criteria. Of the 33 community service respondents, most of the symptoms caused were pain that occurred before and during menstruation within 24 hours
\end{abstract}

Keywords: Dysmenorrhea, Prevention, Dysmenorrhea Exercise, Adolescents 


\section{PENDAHULUAN}

Dismenore hampir dialami seluruh perempuan. Di dunia, angka kejadian sangat besar, rata-rata lebih dari $50 \%$ perempuan disetiap negara mengalami dismenore. Menurut data dari WHO, 2010 didapatkan angka kejadian sebesar 1.769.425 jiwa (90\%) wanita mengalami dismenore dengan 1015\% mengalami dismenore berat. Di Indonesia angka kejadian dismenore sebesar 107.673 jiwa $(64,25 \%)$, yang terdiri dari 59.671 jiwa $(54,89 \%)$ mengalami dismenore primer dan 9.496 jiwa $(9,36 \%)$ mengalami dismenore sekunder. Masalah dismenore setidaknya mengganggu 50\% wanita masa reproduksi dan 60-85\% pada usia remaja, yang mengakibatkan banyaknya absensi pada sekolah maupun kantor. (Sari, 2010; Suparto, 2011).

Salah satu akibat dismenore adalah bisa membantu konsentrasi menurun, tidak ada motivasi untuk kuliah, tidak bisa presentasi secara maksimal, dan bahkan sampai ada yang terpaksa meninggalkan perkuliahan karena sudah tidak tahan dengan nyeri haid yang dirasakan. Terlebih pada orang yang harus bekerja dalam keadaan sakit. Semua hal itu sangat mengganggu dan membuat badan terasa tidak nyaman, bahkan bisa menurunkan produktivitas kerja (Anurogo \& Wulandari, 2011)

Beberapa hasil penelitian yang sudah dilakukan untuk mengurangi nyeri haid, yaitu dengan cara kegiatan teknik distraksi (mendengarkan musik klasik mozart). Hal ini menunjukkan bahwa kurangnya kenyamanan karena responden tidak bisa konsentrasi sepenuhnya seperti terganggu, kurang nyaman, kurang rileks dan kurang tenang. Sehingga teknik ini tidak begitu efektif untuk menurunkan nyeri haid (Armika \& Ari, 2018). Hasil penelitian yang dilakukan Maita (2016), di dapatkan bahwa rata-rata nyeri sebelum melakukan senam adalah 4,30, dengan standar deviasi 2,086. Sedangkan nilai rata-rata nyeri sesudah senam adalah 2,83 dengan standar deviasi 2,085. terlihat sedikit perbedaan nilai mean perbedaan antara nyeri sebelum senam dan nyeri sesudah senam adalah 1,47 dengan standar deviasi 0,001 Hasil uji statistik di dapatkan nilai $\mathrm{p}=0,001$ maka dapat disimpulkan ada perbedaan yang signifikan antara nyeri dismenore sebelum melakukan senam dan nyeri dismenore sesudah melakukan senam.

Dismenore atau nyeri haid merupakan salah satu keluhan ginekologi yang paling umum pada perempuan muda yang datang ke klinik atau dokter (Anurogo, 2011). Dismenore adalah ketegangan yang terjadi pada bagian perut bawah dan sering kali disertai gejala seperti mual, muntah, diare, sakit kepala sebelah (migren) dan pusing (Laila, 2011). Penyebab dismenore bermacam-macam, bisa karena penyakit (radang panggul), endometriosis, tumor atau kelainan uterus, stres atau cemas yang berlebihan, bisa juga karena ketidakseimbangan hormonal dan tidak ada hubungannya dengan organ reproduksi. Faktor-faktor yang menyebabkan dismenore primer antara lain faktor kejiwaan yang secara emosional tidak stabil yang terjadi pada gadis remaja apabila tidak mendapat penerangan yang baik tentang proses haid (Judha, Sudarti, \& Fauziah, 2012), berkaitan juga 
dengan adanya peningkatan hormon prostaglandin yang bisa meningkatkan kontraksi miometrium dan mampu mempersempit pembuluh darah, sehingga terjadi kontraksi otot-otot rahim (Syntia, 2012). Dismenore sekunder berhubungan dengan kelainan kongenital atau kelainan organik di pelvis yang terjadi pada masa remaja. Rasa nyeri yang timbul disebabkan karena adanya kelainan pelvis misalnya endometriosis, mioma uteri (tumor jinak kandungan), stenosis serviks, dan malposisi uterus (Judha, Sudarti, \& Fauziah, 2012).

Dismenore dapat diatasi dengan cara farmakologi dan non farmakologi. Secara non farmakologi dapat dilakukan dengan kompres hangat, mandi air hangat, yoga, distraksi, massase, tidur/istirahat dan olahraga atau senam. Olahraga atau senam dilakukan setiap pagi dan atau sore hari. Baik dilakukan 3-5 kali seminggu selama 30 menit (Martchelina, 2011). Senam dismenore adalah senam yang fokusnya membantu peregangan seputar otot perut, panggung dan pinggang. Selain itu, senam tersebut dapat memberikan sensasi rileks yang berangsur-angsur serta mengurangi nyeri jika dilakukan secara teratur (Badriyah \& Diati, 2010). Adapaun tujuan dilakukan senam dismenore menurut Puji (2010), yaitu: Membantu remaja yang mengalami dismenore untuk mengurangi dan mencegah dismenore, alternatif terapi dalam mengatasi dismenore dan intervensi yang nantinya dapat diterapkan untuk memberikan pelayanan asuhan keperawatan bagi masalah dismenore yang sering dialami remaja.

Senam dismenore merupakan salah satu teknik dalam memberikan kondisi yang nyaman dan rileks pada remaja saat mengalami dismenore. Senam merupakan salah satu teknik relaksasi yang dapat digunakan untuk mengurangi nyeri, hal ini disebabkan saat melakukan senam, tubuh akan menghasilkan endorphin. Endorphin dihasilkan otak dan susunan syaraf belakang. Hormon ini dapat berfungsi sebagai obat penenang alami yang diproduksi otak sehingga menimbulkan rasa nyaman. Senam dismenore, yang terdiri dari gerakan pemanasan, inti dan pendinginan, dan senam ini dilakukan selama 30 menit. Adapun gerakan inti merupakan gerakan peregangan otot-otot perut dan panggul dengan tujuan aliran darah pada otot rahim akan lancar dengan meredahkan rasa nyeri pada saat menstruasi (Abbaspour, 2010).

Penelitian yang dilakukan oleh Nashori (2004) menyatakan bahwa salah satu self-care strategies yang dapat digunakan untuk mengurangi dismenore yaitu dengan cara mengurangi aktivitas fisik serta melakukan bed rest dan tidur. Penelitian Chafira De Nada dan Endang Fouriana listyawati (2017), mengatakan bahwa adanya hubungan yang lemah namun signifikan antara efikasi diri dengan kualitas tidur pada remaja yang mengalami dismenore. Hubungan yang lemah disebabkan karena terdapat beberapa faktor lainnya yang lebih kuat, sehingga menyebabkan remaja yang menderita dismenore memiliki kualitas tidur yang buruk.

Senam dismenore dapat mengurangi nyeri menstruasi karena pada saat melakukan senam dismenore mengalami peningkatan volume darah yang mengalir keseluruh tubuh, termasuk organ 
reproduksi sehingga memperlancar pasokan oksigen ke pembuluh darah, terjadi vasokontraksi otak dan susunan syaraf tulang belakang yang dapat berfungsi sebagai obat penenang alami yang diproduksi otak yang menimbulkan rasa nyaman dan meningkatkan kadar $\beta$-endorphin dalam tubuh untuk mengurangi rasa nyeri (Harry, 2017).

Penangan dismenore secara non farmakologipun cukup bermacam-macam, diantaranya dengan kompres hangat, senam, yoga, nafas dalam, dan self tapping. Gerakan atau terapi non farmakalogis tersebut dapat mempengaruhi peningkatan hormon $\beta$-endorprin ataupun serotonin, terapi non farmakologi bermanfaat terhadap peningkatan hormon $\beta$-endorprin dan serotonin untuk membantu mengurangi keluhan nyeri (Haryatno, 2016). Pelepasan $\beta$-endorprin diketahui dapat menurunkan rasa nyeri ataupun dapat menjadikan tubuh segar. Pelepasan $\beta$-endorprin dapat meningkatkan respon saraf parasimpatis yang menyebabkan vasodilatasi pembuluh darah seluruh tubuh dan uterus sehingga dapat menurunkan rasa nyeri saat dismenore (Ernawati, 2010). Serotoninpun memiliki peran, serotonin atau serotonergik (5-HT) neuro diketahui dapat mengurangi ketegangan fisik, memberikan suatu perasaan yang nyaman serta dapat memberikan suatu perasaan yang dapat memberikan energi yang baru, dan dapat mengurangi nyeri serta kelelahan (Madjid, 2011).

Melakukan senam dismenore dapat menurunkan nyeri menstruasi. Dengan olahraga rutin atau senam terjadi peningkatan volum darah yang mengalir keseluruh tubuh, termasuk organ reproduksi sehingga memperlancar pasokan oksigen ke pembuluh darah yang mengalami vasokontraksi, sehingga nyeri haid dapat berkurang. Endorphin dihasilkan di otak dan susunan syaraf tulang belakang. Hormon ini dapat berfungsi sebagai obat penenang alami yang diproduksi otak yang melahirkan rasa nyaman dan meningkatkan kadar endorphin dalam tubuh untuk mengurangi rasa nyeri pada saat kontraksi. Semakin banyak melakukan senam dismenore maka akan semakin tinggi pula kadar $\beta$ endorphin. Ketika seseorang melakukan senam, maka $\beta$-endorphin akan keluar dan ditangkap oleh reseptor di dalam hipothalamus dan sistem limbik yang berfungsi untuk mengatur emosi. Peningkatan $\beta$-endorphin terbukti berhubungan erat dengan penurunan rasa nyeri. Senam dismenore menghasilkan hormon $\beta$-endorphin yang dapat menurunkan nyeri haid sehingga berfungsi untuk mengatur emosi dan stress sehingga produksi hormon-hormon penyebab nyeri seperti adrenalin, esterogen, progesterone dan prostaglandin dapat dikendalikan dan nyeri haid dapat berkurang atau hilang. Selain itu senam dismenore dilakukan dengan waktu yang tepat yaitu dilakukan 3-5 kali seminggu selama 30 menit. Senam dismenore adalah senam yang fokusnya membantu peregangan seputar otot perut, panggung dan pinggang. Selain itu, senam tersebut dapat memberikan sensasi rileks yang berangsur-angsur serta mengurangi nyeri jika dilakukan secara teratur, tahap-tahap yang tepat serta dilaksanakan dengan prosedur yang tepat. Kepatuhan responden dalam mengikuti senam dismenore, responden kooperatif 
dan mudah untuk bekerjasama dalam melakukan senam dismenore juga berperan penting dalam keberhasilan (Amalia dan Djoko, 2016; Harry, 2017)

\section{MASALAH}

Menstruasi adalah masa perdarahan yang terjadi pada perempuan secara rutin setiap bulan selama masa suburnya kecuali apabila terjadi kehamilan. Pada saat menstruasi, darah yang keluar sebenarnya merupakan darah akibat peluruhan dinding rahim (endometrium). Darah menstruasi mengalir dari rahim menuju leher rahim dan keluar melalui vagina (Laila, 2011). Pada umumnya menstruasi tidaklah sakit, akan tetapi sebagian besar perempuan mengalami nyeri yang disebut disminore. Disminore merupakan salah satu keluhan ginekologi yang paling umum pada perempuan muda yang datang ke klinik atau dokter (Anurogo, 2011). Permasalahan ini dapat berlanjut pada bisa membantu konsentrasi menurun, tidak ada motivasi untuk kuliah, tidak bisa presentasi secara maksimal, dan bahkan sampai ada yang terpaksa meninggalkan perkuliahan karena sudah tidak tahan dengan nyeri haid yang dirasakan. Terlebih pada orang yang harus bekerja dalam keadaan sakit. Semua hal itu sangat mengganggu dan membuat badan terasa tidak nyaman, bahkan bisa menurunkan produktivitas kerja (Anurogo \& Wulandari, 2011).Prevalensi disminore pada remaja cukup tinggi. Di Indonesia angka kejadian dismenore sebesar 107.673 jiwa (64,25\%), yang terdiri dari 59.671 jiwa (54,89\%) mengalami dismenore primer dan 9.496 jiwa $(9,36 \%)$. Dari data maka diperlukan upaya untuk menurunkan disminore pada remaja yaitu dengan upaya peningkatan pengetahuan dan penerapan senam disminore dalam mencegah serangan awal disminore pada remaja.

\section{METODE PELAKSANAAN}

Metode pelaksanaan kegiatan pengabdian masyarakat ini adalah pendidikan kesehatan melalui ceramah dan simulasi. Waktu pelaksanaan di SMK 3 Muhammadiyah Palembang yang dilaksanakan pada tanggal 13 bulan Desember 2019. Sasaran kegiatan adalah siswi SMK 3 Muhammadiyah Palembang berjumlah 33 Orang.

Tabel 1. Proses pelaksanaan kegiatan

\begin{tabular}{|c|c|c|}
\hline No & Kegiatan & Proses \\
\hline & Persiapan & $\begin{array}{l}\text { a. Melakukan koordinasi dengan pihak sekolah dan } \\
\text { penyampaian proposal kegiatan. }\end{array}$ \\
\hline & & $\begin{array}{l}\text { b. Sebelum kegiatan dimulai, } \\
\text { mempersiapkan materi, leaflet, } \\
\text { instruktur dan fasilitator }\end{array}$ \\
\hline & & c. Pemateri melakukan penggandaan Materi \\
\hline & & $\begin{array}{l}\text { d. Menyiapkan alat-alat terkait dengan pemberian } \\
\text { materi misalnya phantom dan LCD }\end{array}$ \\
\hline & & $\begin{array}{l}\text { e. Berkoordinasi dengan Sekolah dengan izin } \\
\text { dikeluarkan oleh sekolah setelah berkoordinasi }\end{array}$ \\
\hline
\end{tabular}




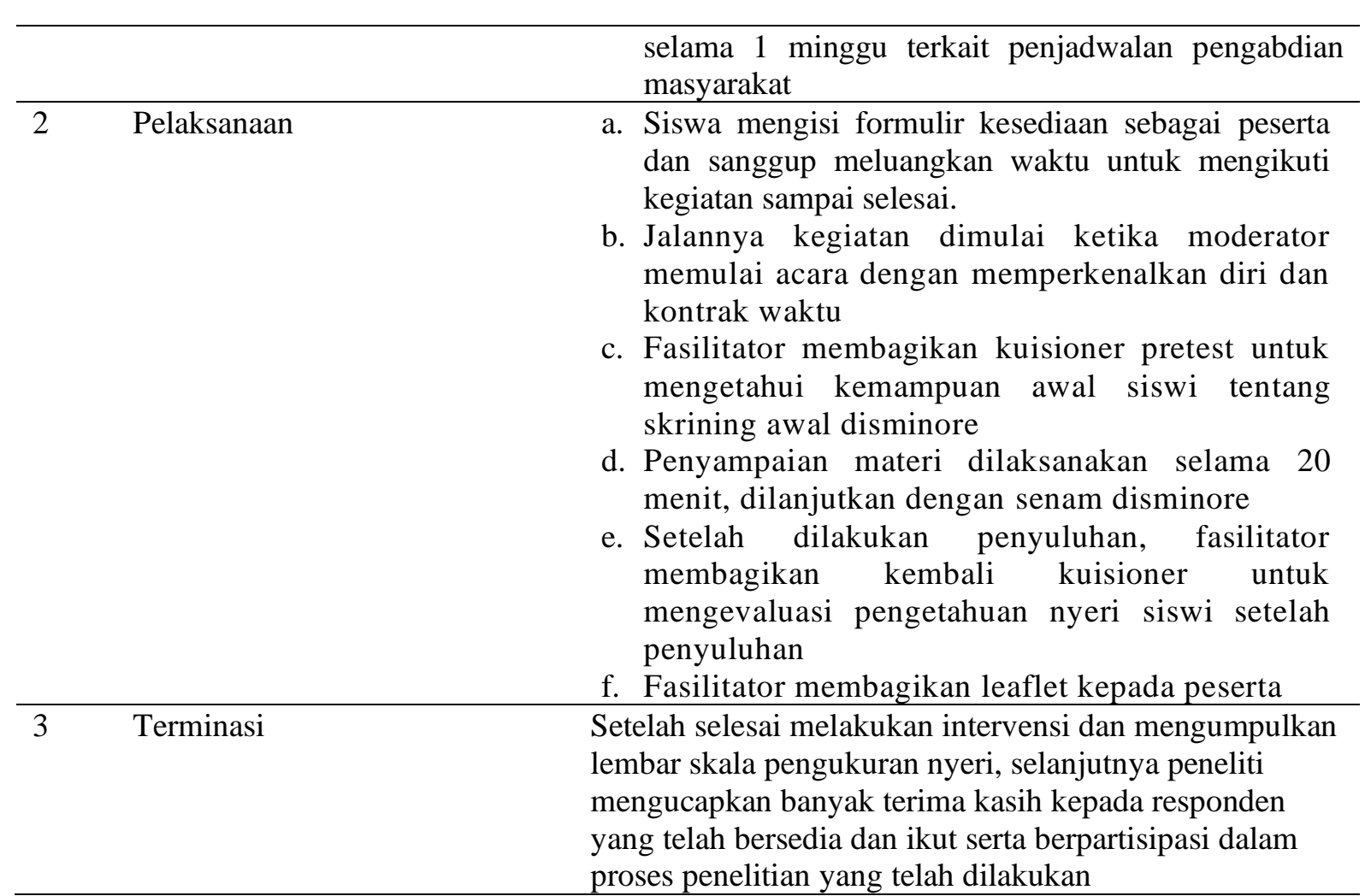

\section{HASIL DAN PEMBAHASAN}

Pengabdian masyarakat telah dilaksanakan pada bulan Desember 2019 di SMK 3 Muhammadiyah Palembang dnegan peserta kegiatan yaitu siswi SMK 3 Muhammadiyah Palembang. Pelaksanaan pengabdian masyrakat ini melallui berbagai proses, diantaranya: Remaja diberikan lembar kriteria dismenore terhadap siswi yang sedang mengalami menstruasi, memberikan penjelasan maksud, tujuan dan kegunaan penelitian terhadap responden., menandatangani inform consent atau lembar persetujuan untuk menjadi responden dalam penelitian., memberikan instrumen penelitian berupa lembar observasi check list sesuai dengan SOP intervensi, mendampingi instruktur senam dismenore kepada responden untuk melakukan senam dismenore.

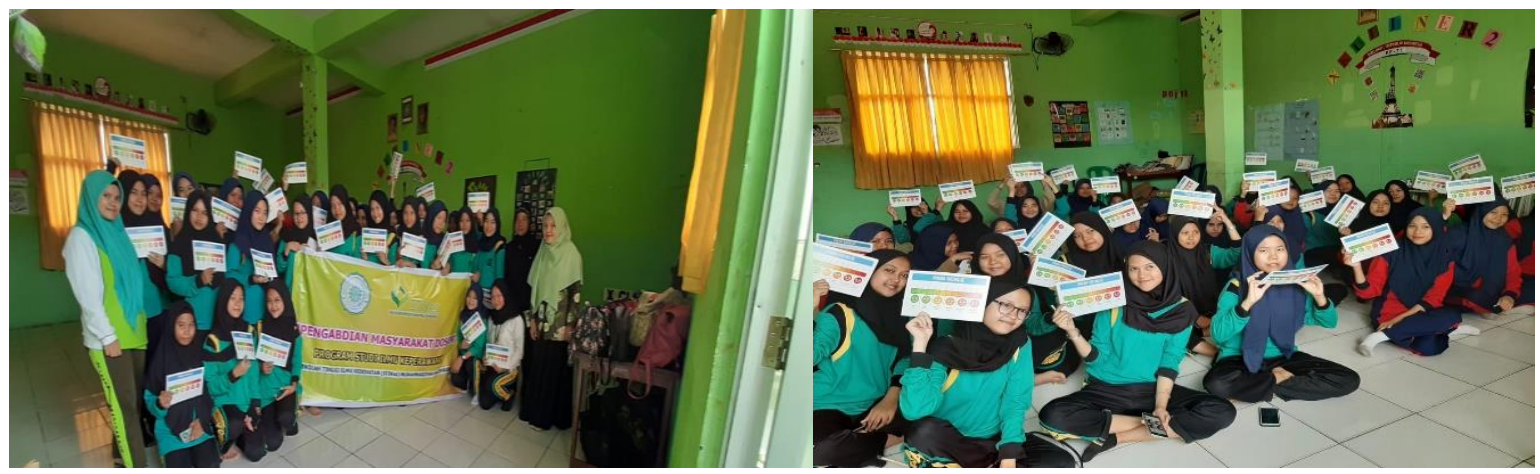

Gambar 1. Proses Pelaksanaan Pengabdian Masyarakat 
Nyeri menstruasi dinilai menggunakan alat ukur Numeric Rating Scale (NRS). Setelah dilakukan pengukuran, masing-masing kelompok melakukan intervensi sesuai SOP selama 30 menit dengan instruktur . Hasil pengukuran nyeri disminore sebelum dilakukan senam disminore yaitu pada tahap nyeri ringan kemudian setelah dilakukan senam disminore rentang nyeri pada kriteria tidak nyeri. Dari 33 responden pengabdian masyarakat gejala yang ditimbulkan sebagian besar yaitu nyeri timbul saat sebelum dan selama menstruasi dalam 24 jam.. Responden merasa senang ketika dievaluasi bagaimana perasaaannya setelah melakukan senam disminore, kemudian responden mengatakan perlu dilakukan senam disminore secara rutin.

Teori H.Hendrawan (2017) menyebutkan bahwa nyeri meningkat disebabkan karena stres pada perubahan fisik dan psikis. Faktor stress ini dapat menurunkan ketahanan terhadap rasa nyeri. Tanda awal yang menunjukan keadaan stress adalah timbulnya reaksi yang muncul yaitu menegangnya otot tubuh indiividu dipenuhi oleh hormon stress yang menyebabkan tekanan darah, detak jantung, suhu tubuh, dan pernafasan meningkat. Disisi lain saat stress, tubuh akan memproduksi hormon adrenalin, estrogen, progesteron serta prostaglandin yang berlebihan. Estrogen dapat menyebabkan peningkatan kontraksi uterus secara berlebihan, sedangkan progesteron bersifat menghambat kontraksi. Peningkatan kontraksi secara berlebihan ini menyebabkan rasa nyeri. Selain itu hormon adrenalin juga meningkat sehingga menyebabkan otot tubuh tegang termasuk otot rahim dan dapat menjadikan nyeri kaetika haid.

Dismenore atau nyeri menstruasi merupakan salah satu keluhan ginekologi yang paling umum pada perempuan muda yang datang ke klinik atau dokter (Anurogo, 2011). Dismenore adalah ketegangan yang terjadi pada bagian perut bawah dan sering kali disertai gejala seperti mual, muntah, diare, sakit kepala sebelah (migren) dan pusing (Laila, 2011). Penyebab dismenore bermacam-macam, bisa karena penyakit (radang panggul), endometriosis, tumor atau kelainan uterus, stres atau cemas yang berlebihan, bisa juga karena ketidakseimbangan hormonal dan tidak ada hubungannya dengan organ reproduksi. Faktor-faktor yang menyebabkan dismenore primer antara lain faktor kejiwaan yang secara emosional tidak stabil yang terjadi pada gadis remaja apabila tidak mendapat penerangan yang baik tentang proses haid (Judha, Sudarti, \& Fauziah, 2012), berkaitan juga dengan adanya peningkatan hormon prostaglandin yang bisa meningkatkan kontraksi miometrium dan mampu mempersempit pembuluh darah, sehingga terjadi kontraksi otot-otot rahim (Syntia, 2012). Dismenore sekunder berhubungan dengan kelainan kongenital atau kelainan organik di pelvis yang terjadi pada masa remaja. Rasa nyeri yang timbul disebabkan karena adanya kelainan pelvis misalnya endometriosis, mioma uteri (tumor jinak kandungan), stenosis serviks, dan malposisi uterus (Judha, Sudarti, \& Fauziah, 2012). 
Berdasarkan hasil pengukuran skala nyeri menstruasi yang mengalami penurunan. Sejalan dengan tori Abbaspour (2010) senam dismenore merupakan salah satu bentuk olahraga yang merupakan rangkaian gerakan secara dinamis yang dilakukan untuk mengurangi keluhan nyeri saat haid. Gerakan yang terdiri dari derakan pemanasan, gerakan inti, gerakan pendinginan, dan dapat dikerjakan secara mandiri, berkelompok atau dengan bantuan dengan instruktur. Tujuan senam dismenore, untuk membantu mengurangi keluhan nyeri pada saat menstruasi dan membantu remaja putri untuk rileks dalam menurunkan nyeri haid (Abbaspour, 2010).

Dismenore ini sendiri dipengaruhi oleh faktor fisik dan psikis seperti stress serta pengaruh hormon prostaglandin. Oleh karena itu dengan melakukan senam disminore, tubuh akan menghasilkan hormon $\beta$-endorphin yang berfungsi sebagai penenang alami di dalam tubuh manusia yang diproduksi oleh otak yang dapat mengurangi stress, menghasilkan rasa nyaman serta mengurangi nyeri saat menstruasi (Puji, 2012).

Berdasarkan hasil skala menstruasi yang mengalami penurunan. Sejalan dengan penelitian Sarifah (2015) hasil penelitian menunjukan bahwa sebelum dilakukan senam dismenore mengalami nyeri haid, sebagian besar dengan nyeri sedang 13 responden (65.0\%). Sebagian besar responden tidak pernah melakukan olahraga, sebelum menstruasi berlangsung. Penerapan senam disminore secara rutin dapat meningkatkan kenyaman pada seorang remaja sehingga menurunkan skala nyeri yang dirasakan. Pengetahuan yang baik dalam mencegah terjadinya serangan disminore dapat menurunkan angka kesakitan akibat masalah menstruasi

\section{KESIMPULAN}

Kegiatan pengabdian masyarakat ini dilakukan berupa edukasi pada siswi SMK dan simulasi senam disminore. Setelah mengikuti kegiatan, Skala nyeri sebelum dilakukan senam dismenore pada siswi SMK 3 Muhammadiyah Palembang didapatkan skala nyeri menstruasi sebelum dilakukan senam dismenore adalah 4,50 dengan nilai minumum 2 dan nilai maksimum 9. Skala nyeri sesudah dilakukan senam dismenore adalah 0,00 dengan nilai minimum 0 dan nilai maksimum 4. Penerapan senam disminore dinilai efektif untuk menurunkan disminore pada remaja.

\section{UCAPAN TERIMA KASIH}

Terimakasih yang sebesar besarnya penulis ucapkan kepada STIKes Muhammadiyah Palembang yang sekarang telah berubah bentuk menjadi Institut Ilmu kesehatan Muhammadiyah Palembang atas bantuan dana melalui danah hibah pengabdian masyarakat, semua pihak yang telah membantu dan memfasilitasi dalam pelaksanaan kegiatan pengabdian masyarakat ini, Sehingga proses 
pelaksanaanya berjalan sesuai dengan rencana yang telah disusun. Ucapan terimakasih kami ucapkan kepada Kepala Sekolah SMK 3 Muhammadiyah Palembang, Ketua STIKes Muhammadiyah Palembang, Ketua Program Studi Ilmu Keperawatan, Ketua Unit Penelitian dan Pengabdian Kepda Masyarakat serta, dan Anggota tim yang terlibat dalam proses pengabdian.

\section{DAFTAR PUSTAKA}

Abidin. (2014). Nyeri Haid pada Remaja. Jakarta: Rineka Cipta.

Ahmad dan Mubiar, (2011). Dinamika Perkembangan Anak dan Remaja (Tinjauan Psikologi Pendidikan dan Bimbingan. Bandung: Refika Aditama.

Andarmoyo, Sulistyo. (2013). Personal Hygiene konsep, proses dan aplikasi dalam praktik keperawatan. Yogyakarta: Graha Ilmu.

Annathayakeisha. (2009). Nyeri Haid. Diakses tanggal 18 Oktober2012.

Apriyanti, Harmia, Andriani. (2018). Hubungan Status Gizi dan Usia Menarche dengan Kejadian Dismenore Pada Remaja Putri di Sman 1 Bangkinang Kota Tahun 2018. Jurnal Maternitas Kebidanan, Vol 3, No. 2

Atikah Proverawati dan Siti Misaroh. (2009). Menarche Menstruasi Pertama Penuh Makna. Yogyakarta: Nuha Medika.

Badziad, A. (2009). Endokrinologi dan Ginekologi. Jakarta: Media Aesculapius

Cerika, R., RR. Wijayanti \& Amelia, A, L. (2013). A Study of Dysmenorrhea During Menstruatioans In Adolscent Girls. Indian Journal of Community Medicine. Vol. 35. Issue.

Choiriyah, A. (2014). Karya Tulis Ilmiah Pengaruh Kompres Hangat Terhadap Penurunan Nyeri Saat Menstruasi Pada Mahasiswi Tingkat III Prodi DIII Kebidanan Stikes Bhakti Husada Mulia Madiun.

Ernawati, Hartati, T. \& Idris, H. (2010). Terapi Relaksasi Terhadap Nyeri Dismenore Pada Mahasiswi Universitas Semarang. Prosiding seminar Nasional.

Fitri, Imelda. (2017). Lebih Dekat Dengan Sistem Reproduksi Wanita. Yogyakarta: Gosyen Publishing. Harry. (2017). Mekanisme Endhorpin Dalam Tubuh. Available from: Http:/klikharry.files.wordpress.com/2007/02/1.doc + endorphin + dalam + tubuh.

Haryatno, Pajar. (2016). Pengaruh Pemberian TENS dan Myofascial Release Terhadap Penurunan Nyeri Leher Mekanik. Jurnal Terpadu Ilmu Kesehatan.

Karim, Anton \& Calis. (2013). Dysmenorrhea. Available from: http://emidicine.medscape.com/article/253812-overview

Kusmiran, E. (2013). Kesehatan Reproduksi Remaja dan Wanita. Jakarta : Salemba Medika. Laila, N. (2016). Buku Pintar Mestruasi Dan Solusi Mengatasi Segala Keluhan. Yogyakarta: Buku Biru. 
Lestari, N.M.S.D. (2013). Jurnal Seminar Nasional FMIPA UNDIKSHA III Tahun (2013). Pengaruh Dismenorea Pada Remaja.

(http://ejournal.undiksha.ac.id/index.php/semnasmipa/article/view/2725/2305).

Madhubala, C dan Jyoti, K. (2012). Relation between dysmenorrhea and body mass index in adolescents with rural versus urban variation. The Journal of Obstetrics and Gynecolog of India.

Maita, Liva. (2016). Pengaruh Senam Dismenore Terhadap Pengurangan Rasa Nyeri Menstruasi Mahasiswa Kebidanan STIKes Hangtuah Pekanbaru. Pekanbaru: STIKes Hangtuah Pekanbaru.

Martchelina, I. (2011). Pengaruh Senam Dismenore terhadap Penurunan Tingkat Nyeri Saat Menstruasi pada Remaja Putri usia 12-17 tahun SMP 131 di Cipedak Kecamatan Jagakarsa. Jakarta: Universitas Pembangunan Nasional Veteran.

Ni Made. 2013. Pengaruh Dismenorea Pada Remaja. Seminar Nasional: FMIPA UNDIKSHA III.

Ningsih, R. (2011). Efektifitas Paket Pereda Terhadap Intensitas Nyeri Pada Remaja Dengan Dismenore Di SMAN Kecamatan Curup. (Tesis). Depok : Fakultas Ilmu Keperawatan Universitas Indonesia.

Simanjuntak, Pandapotan. (2014). Gangguan Haid dan Siklusnya. Dalam: Prawirohardjo, Sarwono, Wiknjosastro, Hanifa. Ilmu Kandungan. Edisi ketiga. Jakarta: Bina Pustaka Sarwono Prawirohardjo.

Sophia, F. \& Muda, S. Jenadi. (2013). Faktor-faktor yang berhubungan dengan dismenore pada siswi SMK Negeri 10 Medan. Jurnal gizi kesehatan reproduksi, dan epidemiologi. 2 (5). Medan: Fakultas kesehatan Masyarakat Universitas Sumatera Utara. 